\title{
Explorando "Arkham Asylum”: sobre vídeo game e aprendizagem inventiva
}

Exploring Arkham Asylum: Video games and inventive learning Exploración de "Arkham Asylum": de videojuegos y aprender inventivo

\section{Carlos Baum}

Universidade Federal do Rio Grande do Sul, Porto Alegre, RS, Brasil.

\section{Cleci Maraschin}

Universidade Federal do Rio Grande do Sul, Porto Alegre, RS, Brasil.

\section{Resumo}

Apesar de sua popularidade e diversidade, os vídeo games são tratados como uma mídia marginal, frequentemente acusados de serem nocivos e prejudiciais a seus jogadores. Neste artigo tomamos em análise o jogo Batman: Arkham Asylum e questionamos quais as divergências que o encontro com o vídeo game e os problemas que ele propõe produzem no processo da cognição. Assumimos uma perspectiva inventiva da cognição, entendendo-a como um processo onde a mesma se diferencia constantemente de si mesma, criando com isso múltiplos e inéditos regimes de operação. A análise aponta para uma nova condição de experiência que pode ser gerenciada para direções ético-estéticas, se nossos preconceitos não nos paralisarem e se nossa capacidade inventiva assim nos permitir.

Palavras-chave: Vídeo game, Jogos eletrônicos, Cognição, Inventiva, Aprendizagem.

\section{Resumen}

Apesar de su popularidad y diversidad, los videojuegos son tratados como un medio de comunicación marginal, a menudo acusados de dañinos y perjudiciales para sus jugadores. En este trabajo se analiza el videojuego Batman: Arkham Asylum para cuestionar las divergencias del encuentro entre el videojuego y los problemas que se propone producir en el proceso de cognición. Tomamos un enfoque inventivo de la cognición, o sea, como un proceso en lo cual uno se difiere constantemente de sí mismo, creando múltiples y inéditos regímenes operativos. El análisis apunta a una nueva condición de la experiencia que puede ser agenciada hacia posturas éticas y estéticas, eso si nuestra capacidad inventiva permitir y nuestros prejuicios no paralizarnos.

Palabras clave: Videojuegos, Juegos electrónicos, el Aprendizaje, Cognición inventiva. 


\begin{abstract}
As the vídeo games grows in variety and popularity they are still treated as a marginal medium. Continually accused of being harmful and damaging to its players. In this paper we analyzed the game Batman: Arkham Asylum and question what the differences that the encounter with the video game and the problems it proposes to produces in the process of cognition. We take an inventive approach to cognition, understanding it as a process where it differs constantly from itself, thus creating multiple and unprecedented operating regimes. The analysis points to a new condition of experience that can only be brokered for ethical and aesthetic directions, unless it's paralyze by our prejudices.
\end{abstract}

Keywords: Video game, Electronic games, Inventive cognition, Learning.

\title{
Introdução
}

Os vídeo games tornaram-se nos últimos vinte anos um dos produtos mais lucrativos da indústria do entretenimento, movimentando bilhões de dólares e não demonstrando nenhum sinal de enfraquecimento mesmo frente as mais diversas crises financeiras. Os jogos eletrônicos crescem em popularidade e variedade e se tornaram a mídia de escolha de uma parcela significativa de crianças, adolescentes e jovens adultos de todas as partes do globo. O Brasil é hoje o quarto maior mercado de jogos eletrônicos do mundo. Segundo dados do Comitê Gestor da Internet no Brasil (CGIBr), cerca de $16 \%$ dos lares brasileiros possuem algum console de vídeo game e $32 \%$ deles, possuem computadores.

Contudo, os vídeo games ainda são considerados uma mídia marginal que poderia induzir ações violentas; causaria automatismos sensório-motores, privando seus usuários de pensamento ou conduziria a uma severa adição fazendo com que seus jogadores desperdicem horas e horas de seus dias em frente à tela de modo compulsivo.

Essas críticas partem geralmente de observadores não imersos, de pessoas pouco familiarizadas com jogos eletrônicos, não alfabetizadas em vídeo games. Se tomarmos alfabetização em um sentido ampliado, entendendo-a como a capacidade de ser efetivo, de agir e de se comunicar em diferentes domínios sóciocognitivos, podemos pensar que jogar videogames implica uma alfabetização. Observar um jogador imerso em um jogo de ação pode parecer a um iletrado nesse campo uma tentativa desesperada de 
esmagar os botões de um controle ou as teclas de um computador. Isso porque a aprendizagem nesse domínio se dá de modo distinto em relação a alfabetização em uma língua escrita, ou a aprendizagem de uma linguagem cinematográfica.

Vamos tentar explorar essa modalidade de alfabetização, tomando a experiência de aprendizado de um jogo de ação chamado Batman: Arkham Asylum (B:AA). Ao nos posicionarmos na perspectiva de um observador imerso buscamos pensar essa aprendizagem não como uma apreensão para repetição, mas como um campo inventivo.

\section{Invenção e Experiência Projetada}

O termo vídeo game é usado ao longo do texto de um modo abrangente, incluindo ambiente digitais onde um operador interfere em suas variáveis seja controlando um avatar ou construindo e gerenciando um sistema complexo como um exército ou uma cidade, seja em um console específico ou computador. No caso em análise, os jogadores têm a oportunidade de controlar o personagem de histórias em quadrinhos Batman que, ao tentar internar o vilão Coringa em hospital psiquiátrico, acaba preso na instituição com o mesmo e com vários de seus vilões. $\mathrm{O}$ jogador, como Batman, deve resolver problemas, derrotar oponentes, impedir os planos do Coringa e libertar-se do asilo.

Dada as circunstancias nas quais a ação se desenrola, podemos questionar em que medida a mesma se configura em uma experiência inventiva. A invenção, não é aqui entendida como uma criação que surge espontaneamente de uma suposta interioridade subjetiva, tampouco como uma iluminação súbita que toma o indivíduo proveniente de um fora de si. Tomamos a invenção a partir de sua origem latina invenire, que significa encontrar relíquias ou compor com restos arqueológicos. Ela se dá através da experimentação, compondo e recompondo com fragmentos que já nos habitavam, não em uma unidade original ou primeira, tampouco uma essência, mas em um processo incessante que constitui sujeito e objeto simultaneamente. Um processo onde a cognição diferencia-se constantemente de si mesma, criando com isso múltiplos e inéditos regimes de funcionamento. A cognição é, nessa perspectiva, seu principal invento (Kastrup, 1999). Serres (1993) fala de um processo de outramento. Inspirados no autor, diríamos que a invenção nunca se efetua a dois: o jogador e o destino, mas a três. Um terceiro lugar - efeito do diferir intervém aí como limiar da passagem sem se conhecer por antecipação o lugar e o uso dessa porta. Um dia, em qualquer 
momento, se passa esse limiar, uma sensação estranha de mudança de fase, de uma nova sensibilidade. Habita-se esse polo da sensibilidade, da capacidade virtual.

O problema da cognição não se encerra, portanto, na solução de problemas, mas se expande na direção da invenção de novos problemas. Nesse processo, tanto a situação problemática quanto o sujeito se reinventam. A cognição problematiza a si mesma, uma vez que faz parte de sua operação diferenciar-se, problematizar os limites dentro dos quais opera.

Assumir essa posição é comprometer-se com a criação de novas formas de existência e com outros modos de entender a constituição da cognição. Não se trata de se perguntar sobre os múltiplos modos de solucionar problemas, mas sim, quais as divergências que o encontro com o vídeo game (e os problemas que ele propõe) produzem no processo da cognição. Deste modo, o que interessa é como essa experiência atualiza modos de agir virtuais, os quais nem mesmo o protagonista sabia possíveis. Habitar um terceiro lugar.

Mas voltemos ao nosso jogo. B:AA inicia com um breve vídeo que apresenta o personagem título prendendo Coringa na instituição psiquiátrica para infratores conhecida como Asilo Arkhan, que dá título ao jogo. Rapidamente tudo se revela um plano do próprio Coringa para prender nosso herói dentro do hospício e assumir o controle da instituição.

A narrativa, contudo, para nesse ponto. O que vemos são paredes cinzas que lembram um misto de hospital e prisão. Batman está de costas para a tela e, enquanto isso, ouvimos ao fundo as risadas do nosso vilão. Contudo, nada acontece. Se movemos o mouse, o angulo de visão muda, como se tivéssemos uma câmera na mão, mas que só pode orbitar ao redor do personagem.

Logo no princípio nos deparamos com o que talvez seja a diferença mais radical entre as narrativas imagéticas e os vídeo games. Enquanto as primeiras são compreendidas através de "leituras"; os vídeo games nada nos dizem se nos posicionarmos como espectadores. Eles não se dão ao conhecimento pela leitura, sua principal forma de compreensão é a exploração. É através da manipulação, em nosso caso imersos como Batman, que se pode estabelecer alguma relação com o jogo. Ao pressionar a tecla adequada o personagem se desloca pelos corredores e a câmera o segue. O que ocorre aqui é uma inversão, o jogador não acompanha a imagem, é ela que segue sua ação. Se, ao assistirmos a um filme, as cenas nos conduzem por uma história; ao jogarmos vídeo game, é a imagem que busca refletir nossas jogadas. 
Jogos eletrônicos são ambientes construídos. Os designers do jogo criam mundos imersivos com regras embutidas e relações entre objetos que permitem experiências dinâmicas. Essa organização espacial serve, em termos gerais, para criar uma atmosfera que encoraje a performance do jogador, a competitividade ou a colaboração, de acordo com cada caso. Esses elementos e regras definem os termos iniciais da experiência dos jogadores. O ambiente é projetado para apresentar aos jogadores objetivos claros (escapar do hospital e derrotar o Coringa), de modo que estimule o jogador a identificar os problemas e desenvolver planos de solução. Cada um desses espaços possui muitos pontos de entrada e saída e diversos caminhos possíveis, dando oportunidade para jogadores lidarem de modo criativo com esses problemas (Squire \& Jenkins, 2002).

Squire (2006) propõe que os vídeo games possam ser entendidos como uma experiência projetada, um contexto onde experimentação ocorre. Nesses mundos, o importante é compreender os modos de habitá-los, compreendendo os mecanismos utilizados para criar sentidos e como esses sentidos e experiências emergem.

\section{Uma Aprendizagem Inventiva}

O jogo em tela, pensado como experiência planejada, convida o jogador a habitar esse espaço virtual através de um personagem, tomando suas motivações, objetivos e habilidades como seus. As cenas iniciais do jogo em questão nos permitem compreender onde nos encontramos como protagonista e por que devemos procurar pelo vilão.

O avanço só é possível se o jogador conseguir interpretar os elementos dispostos no cenário. Essa interpretação porém só pode ser feita através da compreensão do campo de possibilidades de ação do personagem e de como essas ações interagem com o espaço do jogo (Gee, 2008). Ao enfrentar múltiplos inimigos de Batman, o jogador precisa simultaneamente acompanhar a posição e os movimentos de seus oponentes, identificar quais dos seus próprios movimentos podem ser utilizados na situação e ser capaz de julgar a ordem de prioridades adequada para que todos sejam derrotados. O que para um espectador, em um primeiro momento, poderia aparecer somente uma cena de ação violenta que requer do jogador uma disposição agressiva, se mostra uma ação cognitiva complexa que requer constante classificação, ordenação e configuração de ações coordenadas com a disposição do sistema (Squire, 2005).

Os sons e animações são sinais da condição do jogo que precisam ser usados constantemente para organizar a ação do 
jogador. Para alguém não familiarizado, esses diversos sinais podem ser incompreensíveis ou podem mesmo nem ser reconhecidos como sinais que precisam de atenção (Squire, 2005). Tomemos como exemplo a figura 1 (em anexo).

Alguém que jamais tenha interagido com o jogo dificilmente seria capaz de atribuir sentido a todos os símbolos contidos na imagem, é possível que não consiga nem mesmo compreender um significado mais geral da cena apresentada. Um jogador experiente, porém seria capaz de identificar pelo menos três símbolos importantes de acordo com o conhecimento que tem do próprio personagem:

1) Um inimigo em vermelho, próximo ao centro da tela, empunhado uma arma. É de conhecimento comum que Batman, apesar de ser um super-herói, não possui super poderes. Enfrentar um vilão armado frente a frente é uma estratégia pouco perspicaz que provavelmente levaria à derrota.

2) Um ponto amarelo bem ao centro da tela que se encontra em uma parede translúcida. Esse ponto representa uma fragilidade da estrutura da parede. Essa fragilidade se mostra importante, pois um dos itens que Batman carrega em seu "cinto de utilidades" é um explosivo de pouca potência que não seria capaz de derrubar um prédio, mas poderia quebrar uma estrutura já danificada. Como essa parede aparentemente está nas costas do inimigo, derrubá-la o pegará de surpresa. Com alguma sorte, talvez o incapacite.

3) Por último, podemos notar uma gárgula de cor laranja na parte superior da imagem, mais ao fundo. Aqui, um conjunto mais complexo de informações é necessário para que o objeto se destaque realmente. É preciso perceber que, tal como informado pelo quadro à direita da imagem, existem mais cinco inimigos na próxima sala além do que está em foco no momento, todos eles armados. O barulho da explosão irá alertá-los e se eles o encontrarem sua chance de sucesso cairá para quase zero. As gárgulas, porém, possuem um status de local seguro, segundo as regras do jogo. Enquanto estivemos sobre elas, não podemos ser encontrados pelos inimigos. É preciso saber ainda que o gancho com corda é capaz de nos conduzir a locais mais altos.

É preciso construir uma sintonia com os movimentos e possibilidades do jogo e, a partir disso, coordenar os movimentos. Não basta que conheçamos os movimentos possíveis através de uma descrição, é preciso ao longo do jogo construir uma competência corporal que gradualmente inclua as possibilidades do avatar e as disposições do cenário, alargando a percepção do jogador, que capta aspectos cada vez mais finos e 
variáveis que vão tomando parte na composição do seu campo cognitivo.

É importante notar que o protótipo do aluno em uma aprendizagem inventiva não é aquele somente capaz de solucionar problemas adequadamente. Poderia ser comparado a um estudante de música, que pode começar seu aprendizado através de instruções simbólicas, mas que consuma sua aprendizagem quando a relação simbólica é transformada em acoplamento direto do corpo com o instrumento, eliminando o intermediário da representação. Aprender não significa adequar-se ao instrumento, mas agenciarse com ele. $\mathrm{O}$ agenciamento não implica subordinação ou hierarquia, tão pouco opera por causalidade, mas por uma implicação recíproca de fluxos heterogêneos, por uma dupla captura, resultando na diferenciação de todas as linhas envolvidas (Kastrup, 2008). Maturana (1997) vai definir esse movimento como uma transformação estrutural na convivência, não sendo nem da ordem da incorporação, nem da expressão.

É preciso que o jogador permita que o personagem o habite ou, nas palavras de Gee (2007), que se torne um hibrido com o personagem. Essa multiplicação e refinamento dos traços percebidos recorrem ao campo inventivo da cognição, que passa a atualizar-se na criação de soluções locais e inéditas. Uma vez que uma das características principais dos vídeo games é justamente impedir que o jogador rotinize o uso do aprendizado, pois a cada vez que uma solução foi construída, um novo conjunto de problemas emerge mantendo o jogo sempre no limiar da competência do jogador. Se, eventualmente, os desafios tornam-se muito fáceis, o jogador fica entediado, se muito difíceis, ele fica frustrado. Os game designers se utilizam de diversas técnicas para construir uma sensação que pode ser descrita como "difícil, mas justo" (Gee, 2009).

$\mathrm{O}$ que se produz nessa aprendizagem não é uma repetição mecânica, mas uma atividade criadora que elimina o determinismo do objeto. Aprende aquele que cria permanentemente na relação, reinventando-se também de maneira incessante.

Não aprende melhor aquele que toca uma música sempre da mesma forma, mas aquele que é capaz de interpretá-la, aquele que, em suas repetições, é capaz de um maior número de variações. E é justamente aí que reside o lugar da repetição na aprendizagem, ela serve para corporificar o conhecimento, eliminando a análise e a representação. Repetir não é criar automatismos, hábitos mecânicos. A repetição tem a função de criar uma intimidade com o objeto, até encarná-lo e, 
com isso, espantar a mediação da representação (Kastrup, 2008). Encarnar, enatuar, distingue-se de introjetar, pois como afirmam Maturana e Varela (1990), não existem interações instrutivas. A aprendizagem resulta de uma mudança estrutural que se agencia na convivência, que altera o corpo e o mundo no qual o corpo se acopla.

É preciso então que o jogador se engaje em um incessante processo de invenção de critérios de pertinência e o abandono de regras gerais em favor de táticas locais e imediatas. Esse processo diminui, gradualmente, o papel exercido pelas representações conscientes, com a progressiva corporificação do conhecimento, mais rápido e imediato, resultando em uma fluidez de movimentos e sincronia com o ambiente que se dá através de um acoplamento direto, sem a mediação da consciência. Correspondo a uma imersão cada vez maior no domínio cognitivo que quem opera, para usar as palavras de Kastrup (2000):

...no momento em que o dispositivo se acopla com a inteligência, esta é coloca em um processo de virtualização, acionando processos de criação e de diferenciação em seu interior. Ao final, o uso dos dispositivos técnicos responde, nesse sentido, por um processo de transformação da forma de funcionamento da cognição (p. 41)
Essa aprendizagem não se limita em transformar a desatenção em atenção ou a semiconsciência em apreciação. Diferentemente do automatismo, ela ensina o corpo a ser afetado, ou ser efetuado, pela influência dos sinais do jogo, que anteriormente atingiam o jogador, mas não o faziam agir, não o tornavam atento. Qualquer conjunto de símbolos produzia o mesmo efeito geral e indiferenciado. Com o acoplamento cada signo na tela gera uma diferença no jogador, que vai gradualmente se articulando com o jogo e aprende a ser afetado por ele. É através de novas configurações de conduta que novos objetos podem surgir para o jogador e assim constituem-se concomitantemente um domínio de distinções e um domínio de ações coordenadas, como objetos e não como representações.

Dessa transformação estrutural resulta um maior número de situações e objetos discrimináveis e um maior número de respostas apropriadas. Desse modo, apreender um vídeo game corresponde a criação de uma conduta inventiva, que produz simultaneamente o próprio território onde ela se estabelece. Enquanto apreendo e executo novos movimentos, também construo uma narrativa imagética a partir das decisões que tomo. Contudo, isso só pode ser feito a partir de uma prática concreta naquele domínio cognitivo 
que emerge da interação entre jogo e jogador (Kastrup, 2000).

\section{Considerações Finais}

Cabe ressaltar que existem vídeo games mais restritos, mas esses não são os que tendem a perdurar. Os games, cada vez mais, tem sido concebidos no sentido de aceitar diferentes modos de jogabilidade, tais como os jogos multiplayers, os jogos com realidade expandida e os jogos que permitem que o jogador possa modificar parâmetros, tendo acesso a sua programação. Alem disso, um jogo sempre apresenta um problema, um enigma a ser resolvido por aqueles que jogam. Essa é uma outra forma de adensar a experiência no momento do jogar.

Assim como aprender uma língua, a alfabetização não se encerra na capacidade de decodificar as palavras (como ler), mas espera-se também que o aprendiz compreenda um certo conjunto de práticas e seja capaz de produzir (como escrever) nesse meio. No caso dos vídeo games essas habilidades encontram-se fortemente interligadas, é sua própria prática que pode levar a configuração de objetos diversos. Uma analogia possível seria a capacidade de perceber, através da escrita, distinções cada vez mais refinadas de significados de palavras.
Novas distinções levam o jogador a construir outras questões no jogo, expandindo constantemente o domínio interativo e os problemas possíveis dentro de um jogo. Assim, existe uma experimentação de como a ação é produtora de objetos. Podemos dizer que nos jogos temos ferramentas para experimentar como a ação leva a imagem num circuito de reciprocidade que produz sentido e narrativa.

A imagem/objeto assim posta passa a ser uma experiencia que convoca sempre uma problematização (breakdown), no sentido de Varela (1997). Ação-imagem que suscita nova ação, não se deixando apreender, porque cada vez que se alcança uma etapa o jogo propõe novos desafios. Cada vez que se passa de uma fase, existe outra mais difícil. Assim, o vídeo game convoca a uma problematização que não parte de um distanciamento abstrato, que diante de um problema faz pensar "o que fazer?" Ao contrario, trata-se de ingressar no próprio âmago problemático e tomar a ação como constitutiva de um "vamos fazer"... "vamos fazer aparecer", fazer o que se vê, viver a imagem.

Essa é uma disposição a invenção através da qual é possível:

Entrar na espessura do problema é (...) tocá-lo de maneira não representativa, é problematizar-se com ele. (...) A invenção 
depende, portanto, de uma abertura para um campo de multiplicidades ou, antes, para o que existe de diferencial no objeto, para o que não foi codificado na representação (Kastrup, 1999, P. 80)

Nessa perspectiva, quando se busca julgar os vídeo games sem entrar na espessura do problema, pode-se facilmente cair em um juízo moral ou disciplinador. Uma vez que para um observador imerso, a ação esta dada no contexto do jogo e não há necessariamente uma passagem direta entre diferentes contextos de ação, pois cada quais contem congruências operacionais próprias. Uma ação, que no contexto do jogo, pode fazer parte da solução de um problema, não é lógica nem necessariamente enatuada em outros contextos, para um observador encarnado. Assim, necessitamos ter cautela quando atribuímos aos jogadores assíduos tendencias violentas ou competitivas que seriam diretamente transferíveis a outros contextos de experiência. Longe de postularmos a neutralidade dos games, pensamos que tal como outros produtos culturais, os vídeo games são forjados e convocam a experimentação com a complexidade, as contradições, os limites e possibilidades da experiência coletiva.

\section{Referências}

Gee, J. P. (2007). What video games have to teach us about learning and literacy. New York: Palgrave Macmillan.

Gee, J. (2008). Video Games and Embodiment. Games and Culture, v. 3, n. 3-4, p. 3-4.

Gee, J. P. (2009). Bons videogames e boa aprendizagem.

Perspectiva, Florianópolis, 27(1), 167-178, jan./jun.

Kastrup, V. (1999). A invenção de si e do mundo: uma introdução do tempo e do coletivo no estudo da cognição. Campinas, São Paulo: Papirus Editora.

Kastrup, V. (2000). Novas tecnologias cognitivas: o obstáculo e a invenção. In Pellanda, N.M.C. \& Pellanda, E.C. (Org.). Ciberespaço: um hipertexto com Pierre Lévy. Porto Alegre: Artes e Ofícios.

Kastrup, V. (2008). A cogniçäo contemporânea e a aprendizagem inventiva. In Kastrup, V. \& Passos, E. (Orgs.). Políticas da Cognição. Porto Alegre: Sulina.

Maturana, H. (1997). A ontologia da realidade. Belo Horizonte: UFMG.

Maturana, H. \& Varela, F. (1990). El árbor del conocimiento: las bases biológicas del entedimiento humano. 
(7.ed.). Santiago del Chile: Editorial Universitária.

Serres, M. (1993). Filosofia Mestiça. Rio de Janeiro: Nova Fronteira.

Squire, K. D. (2006). From Content to Context: Videogames as Designed Experience. Educational Researcher, 35(8), 19-29.
Squire, K.D. \& Jenkins, H. (2002). The Art of Contested Spaces. In Ed. Game On! London: Barbican.

Varela, F. (1994). Conhecer. Lisboa: Instituto Piaget.

\section{Figura}

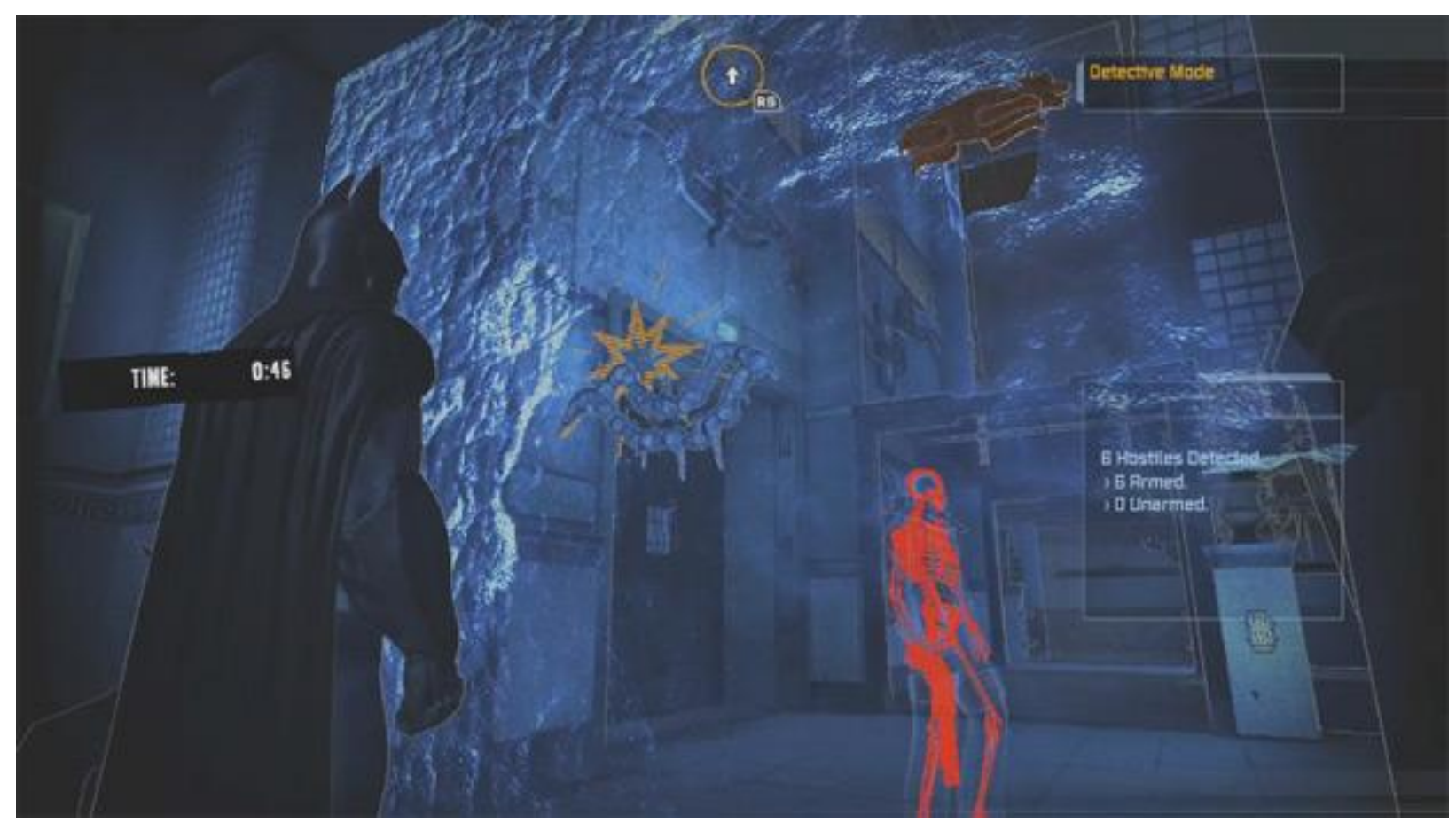

Figura 1- Imagem do jogo Batman: Arkhan Asylum. Na cena, o jogador precisa derrotar seis oponentes armados para prosseguir jogando.

Carlos Baum: Psicólogo, mestrando em Psicologia Social e Institucional UFRGS e pesquisador do grupo Oficinando em Rede. E-mail: baum.psico@gmail.com
Cleci Maraschin: Professora associada do Depto de Psicologia Social e Institucional UFRGS. Docente e orientadora dos PPGs de Psicologia Social e de Informática na Educação. Pesquisadora CNPq. E-mail: cleci.maraschin@gmail.com 